\title{
Acute Schistosomiasis: Report on Five Singular Cases
}

\section{JR Lambertucci ${ }^{+}$, AAM Rayes, CH Barata, R Teixeira, R Gerspacher-Lara}

\author{
Departamento de Clínica Médica, Faculdade de Medicina, Universidade Federal de Minas Gerais, Av. Alfredo \\ Balena 190, 30130-100 Belo Horizonte, MG, Brasil
}

The cases of five patients with unusual manifestations of acute schistosomiasis mansoni are described in this paper. One patient developed skin lesions, three displayed diverse lung involvement, and one presented pyogenic liver abscesses caused by Staphylococcus aureus.

Key words: schistosomiasis - pneumonia - dermatitis - liver abscess

The acute phase of schistosomiasis is usually asymptomatic but clinical signs of varying intensity may occur. Those living in endemic areas may develop the syndrome after having contact for the first time with water contaminated by Schistosoma mansoni cercariae. The most common manifestations are fever, chills, weakness, weight loss, headache, nausea, vomiting, diarrhoea, hepatomegaly, splenomegaly and marked eosinophilia. Fever and eosinophilia occur in several invasive helminthic infections including tropical eosinophilia, visceral larva migrans, trichinosis and liver flukes (Zilberg et al. 1967, Lambertucci 1993a, b).

Schistosomiasis may cause such diverse symptoms that it is not suspected as a cause of disease, especially in non-immune persons. Patients with acute schistosomiasis mansoni have been diagnosed at times as having typhoid fever, hepatitis, pancreatitis and appendicitis, only to be cured when infection with schistosomiasis has been discovered after a long search (Neves et al. 1993). Conversely, all sorts of conditions have been ascribed to schistosomiasis just because a concurrent infection has been discovered in an endemic area where schistosomiasis is common (Amer 1982, Lambertucci et al. 1996).

The cases of five patients with singular manifestations of acute schistosomiasis are herein described. The value of new imaging techniques like sonography (Lambertucci et al. 1994) and computed tomography in improving the accuracy of the diagnosis is emphasized.

\section{CASE REPORT}

Patient 1 - The patient aged 45 was a male lieutenant of the Brazilian Army who enjoyed good

Parcially supported by $\mathrm{CNPq} / \mathrm{Brazil}$.

${ }^{+}$Corresponding author. Fax: +55-31-273.4985

Received 16 April 1997

Accepted 30 June 1997 health until 12 days before admission to hospital when he became ill with colicky abdominal pain, high spiking fevers, loss of weight, and watery diarrhoea (3-4 bowel movements/day) without mucous or blood. Fifty days earlier, during military manouvres, he bathed in a pond, later on found to be colonized with Biomphalaria glabrata, and some of them eliminated cercariae in the laboratory. On examination he appeared acutely ill with adynamy, hyporexia and toxaemia. There was tenderness to palpation over the right side of the abdomen. The liver and spleen were not palpable. The lungs were clear and a chest $\mathrm{x}$-ray revealed no abnormality.

Abdominal ultrasonography showed non-specific increase in the size of the liver and several lymph nodes in the periportal region. The total leukocyte count was 10,800 with eosinophilia $(4,212 /$ 1). Stool examination displayed viable eggs of $S$. mansoni (36 eggs/gram of faeces).

After three days in hospital he developed multiple, small, well circumscribed papulo-erythematous lesions (some with central necrosis) over the chest (Fig. 1). A skin biopsy neither disclosed eggs nor $S$. mansoni worms but perivascular inflammatory cells and eosinophils suggesting vasculitis were observed in the fragments examined by optical microscopy. With a diagnosis of acute schistosomiasis treatment with prednisone and oxamniquine was started with prompt improvement of general signs and symptoms. The cutaneous lesions cleared accordingly within five days.

Patient 2 - A 17 years old boy bathed in stream water of an endemic area for schistosomiasis in the outskirts of Belo Horizonte, State of Minas Gerais, Brazil. He could not recall any itching of the skin at that time and remained in good health for 55 days. Then, and thereafter, he felt uneasy and sick with fever, chills, sweats, weight loss, abdominal pain, bloody diarrhoea, and his appetite was poor. $\mathrm{He}$ also developed persistent dry cough and became slightly breathless. He had been unsuccessfully 


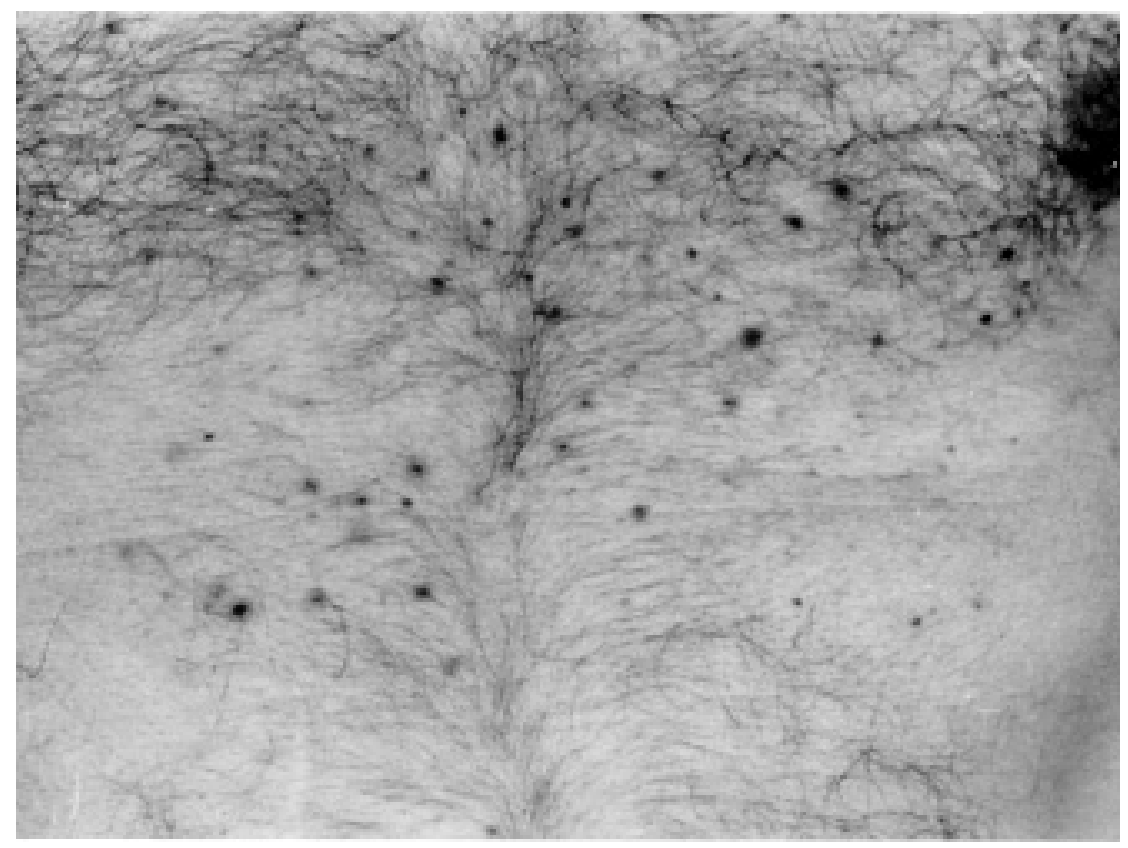

Fig. 1: papulo-erythematous lesions over the chest in a patient with acute schistosomiasis.

treated with antibiotics for "pneumonia" in another hospital. On admission he appeared ill. His skin was warm and humid. Examination showed rales scattered over both lungs, and hepatosplenomegaly. His abdomen was tense and painful to superficial palpation.

Laboratory findings included a hemoglobin of $15 \mathrm{~g} / \mathrm{dl}$, white blood cell count of 19,600 with 8,232 eosinophils. Stool examination revealed 4,608 eggs of $S$. mansoni per gram of faeces. On the fragment obtained by liver biopsy there were necrotizing granulomata around $S$. mansoni eggs. X-ray examination of the chest showed bilateral infiltrates with a few micronodules but a CT-scan unveiled micronodules disseminated in both lung fields.

The patient improved consistently without treatment and was asymptomatic 14 days after entering the hospital. Before dismissal he received praziquantel ( $40 \mathrm{mg} / \mathrm{kg}$, body weight, single dose) and $9 \mathrm{hr}$ later developed a temperature of $39.6^{\circ} \mathrm{C}$ with recurrence of previous signs and symptoms (diarrhoea, abdominal pain, tiredness). He received supportive therapy and left the hospital feeling well four days later. For the next six months, during his follow up at the outpatient clinic, he denied any further complaint.

Patient 3 - A 54 years old nonsmoking black man experienced fever, vomiting, lassitude, and diarrhoea 40 days after bathing in a lake in Santana do Riacho, a small town near Belo Horizonte. He was seen by a physician of a local hospital. Investigations on the occasion showed a white blood cell count of 22,400 with 11,800 eosinophils, and $S$. mansoni eggs in the stools. He was treated for schistosomiasis with oxamniquine $(15 \mathrm{mg} / \mathrm{kg}$, body weight, single dose). The patient remained pyrexial, with nausea, abdominal pain and passing loose stools for the following eight days when he presented dry cough, wheezing and uncharacteristic thoracic pain and was referred to our hospital. Results of roentgenogram of the sinuses, and urinalysis were normal. He lost $2 \mathrm{~kg}$ since the beginning of the symptoms but denied anorexia. He admitted skin itching during the infecting bath that improved spontaneously in two days. Four members of his family, bathing at the same place, developed similar symptoms.

At the time of admission his general status was good with normal vital signs, except for a temperature of $37.7^{\circ} \mathrm{C}$. On examination his skin was unremarkable. The right lobe of the liver was palpable 4 $\mathrm{cm}$ below the right costal margin and was painful to palpation. Chest auscultation revealed coarse crackles confined mainly to the middle and lower zones of both lungs. Chest radiograph confirmed bilateral patchy consolidations (Fig. 2). CT-scan of the thorax demonstrated patchy infiltrates of the left lower lobe and right middle lobe. Neither mediastinal lymphadenopathy nor pleural involvement was found. 


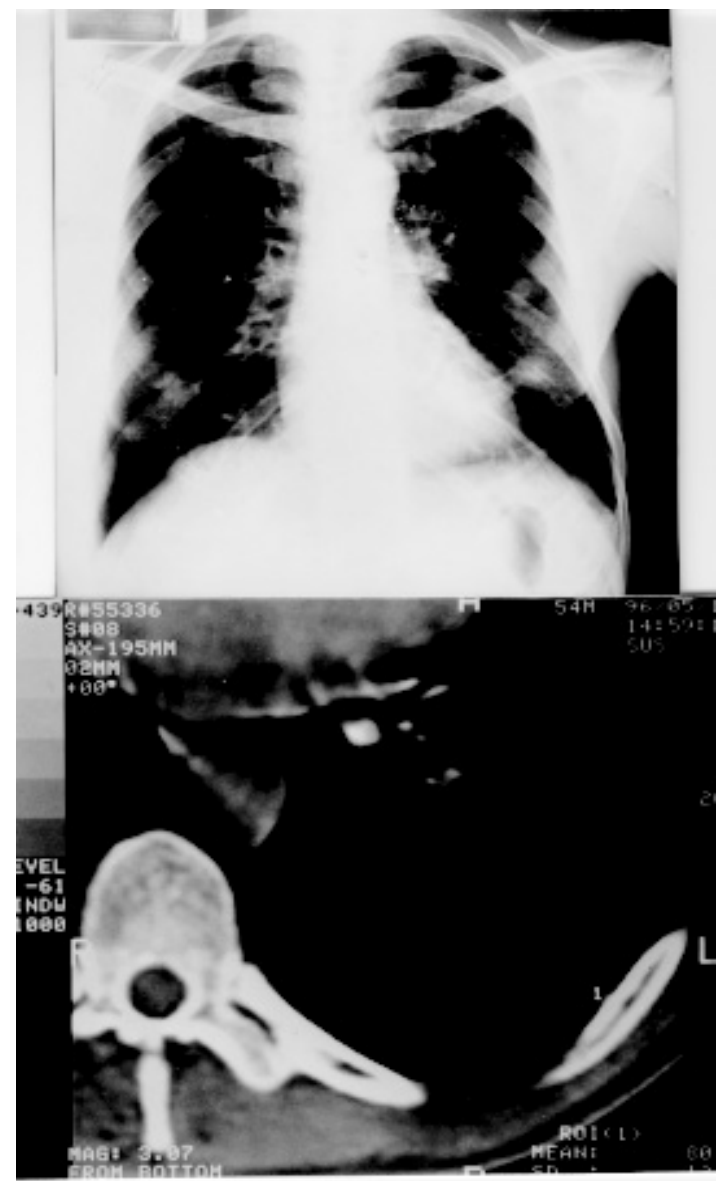

Fig. 2: chest radiograph showing bilateral patchy consolidations in a patient with acute schistosomiasis. CT-scan of the thorax confirms consolidations in the left lower lobe.

The patient was treated with prednisone for seven days and improved quickly. At the outpatient clinic, two months later, all symptoms and roentgenogram infiltrates had disappeared.

Patient 4 - A 15 years old girl was admitted to hospital because of a 20 day history of right chest pain, dyspnoea and cough, fever, vomiting and hyporexia. She came to our hospital escorting her father (Patient 3). Physical examination revealed an alert well-built female with normal vital signs. She had a respiratory rate of 20 breaths per minute. There were no abnormal sounds on pulmonary auscultation. She was apyrexial with no cyanosis, or palpable lymphadenopathy. The liver and spleen were not palpable.

Initial investigations showed a leukocyte count of 14,100 with 6,800 eosinophils and viable eggs of
S. mansoni in the stools. Urinalysis showed hematuria and bacteriuria. Abdominal sonography revealed several periportal lymph nodes and a slight increase of the left lobe of the liver. Sonography also showed obstructive nephropathy of the left urinary tract probably of congenital origin (left ureteropelvic junction obstruction).

The chest radiograph was normal. Notwithstanding, computed tomographic scan demonstrated an area of dense consolidation in the basal segment of the right middle lobe of the lung (Fig. 3).

She received oxamniquine and prednisone and was discharged from hospital feeling well. She is taking trimethoprim-sulfamethoxazole for asymptomatic bacteriuria and has been submitted to monthly clinical examinations. An elective surgery for correction of the urinary tract obstruction is

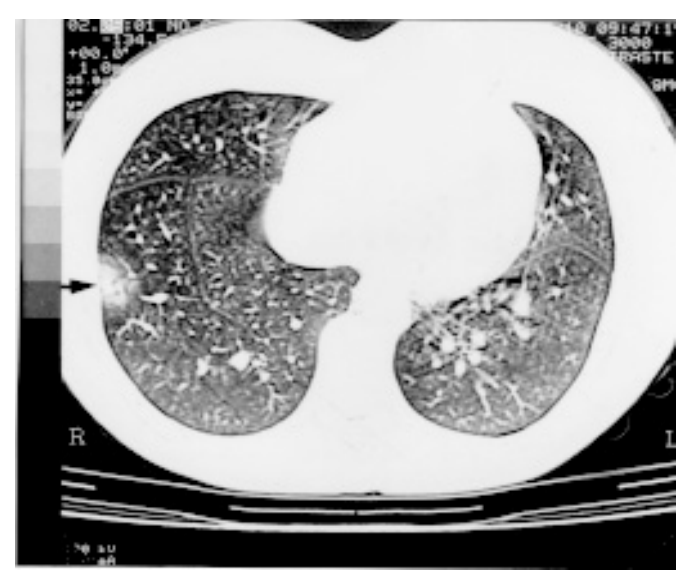

Fig. 3: area of dense consolidation in the basal segment of the right middle lobe of the lung (arrow head).

being considered.

Patient 5 - A 14 years old boy developed intermitent nausea, vomiting and fever associated with increasing lethargy and anorexia 21 days prior to admission. Two days before admission he noticed a tender mass in the right upper quadrant of his abdomen.

On physical examination he was a thin, pale, chronically ill child in no acute distress. His temperature was $38.5^{\circ} \mathrm{C}$, pulse rate $92 / \mathrm{min}$ and blood pressure 100/70 mm Hg. Examination of head, eyes, nose, throat, chest and cardiovascular system was normal. A recent scar of a furuncle was identified on his left foot. His abdomen was soft with a moderately tender, warm, firm mass approximately $4 \mathrm{~cm}$ in diameter palpable below the right costal margin. The spleen was palpable $4-5 \mathrm{~cm}$ below the left cos- 
tal margin and the liver $6 \mathrm{~cm}$ below the xyphoid.

Laboratory investigations included a hematocrit of $32.5 \%$, and a white blood cell count of 23,400 , with 7,250 eosinophils. Urinalysis was normal. Chest roentgenogram was normal. He had a serum albumin of $2.3 \mathrm{~g} / \mathrm{dl}$ and high serum levels of alkaline phosphatase (three times over the normal value). Stool examination disclosed eggs of $S$. mansoni. Three blood cultures revealed no pathogen. Abdominal sonography demonstrated two hepatic abscesses, the large one in the right lobe of the liver corresponding to the mass palpated on physical examination.

The patient received oxacillin and amikacin, combined with percutaneous drainage of the abscesses. Staphylococcus aureus was isolated from the cultures of pus taken on the occasion. Four days later the patient defervesced and remained afebrile. Following clinical improvement he was treated for schistosomiasis with oxamniquine and was discharged, in good shape, on a prolonged course of monthly intramuscular benzathine penicillin $\mathrm{G}$.

\section{DISCUSSION}

The toxaemic form of schistosomiasis mansoni is considered an unusual clinical manifestation of the disease especially in endemic areas for this parasitosis. This is due to the frequent tendency of schistosomiasis to exhibit a clinically non-apparent form in its early phase or to present clinical features similar to those of several infectious or non-infectious diseases prevalent in endemic areas for this helminthiasis (Rocha et al. 1996). We have here presented the cases of five patients with acute schistosomiasis and clinical features which are unfamiliar to most physicians working in endemic and in non-endemic areas of schistosomiasis.

Patient 1 had skin lesions scattered over the chest and a skin biopsy revealed perivascular inflammatory cells composing a picture compatible with systemic vasculitis. As ova of S. mansoni have not been found in the skin fragment studied a possible explanation for the cutaneous lesions is that there was local deposition of immune complexes. Circulating immune complexes have already been demonstrated in the sera of patients with acute schistosomiasis (Hiatt et al. 1979, Gazzinelli et al. 1985). Taliberti et al. (1978) described a unique case of acute schistosomiasis associated with pleural and pericardial effusion and the most probable interpretation of their findings, characterized by them as diffuse serositis, was also a manifestation of regional deposition of immune complexes. In most reported cases, though, pruritic papular lesions on the trunk are caused by ectopic cutaneous laying by of ova (Bittencourt et al. 1979, Milligan \& Burns 1988, Dickinson et al. 1990). It is also possible that, in our case, a second skin biopsy of another nearby area would reveal the $S$. mansoni eggs or worms missed in the first skin fragment.

Patients 2 and 4 are good examples of the pulmonary involvement observed in the acute phase of schistosomiasis. Micronodules disseminated in both lung fields have been described in acute schistosomiasis (Ritchken \& Gelfand 1954, Gelfand 1966) and, as far as we know, this is the first case documented by computed tomographic scan (Lambertucci et al. 1996). The miliary distribution of eggs, known to occur in the acute phase of the disease, should be sufficient to explain this singular clinical presentation of acute schistosomiasis.

Interestingly, pulmonary involvement in patient 4 was only revealed by computed tomography. Roentgenogram of the chest has been useless in pinpointing the pulmonary consolidation, otherwise easily recognized on the film obtained by CT-scan of the lungs. The widespread use of new imaging techniques will certainly identify more patients with pulmonary alterations (Barbosa et al. 1995).

Patient 3 in our viewpoint presented a Löefflerlike syndrome due to lung deposition of embolic worms or/and immune complexes produced by dead worms after chemotherapy with oxamniquine (Lambertucci et al. 1982, Greco et al. 1987, Doenhoff et al. 1988). As we know, praziquantel kills the worms a few hours after treatment but oxamniquine takes 7 to 10 days to have the same effect (unpublished observations). This should explain the recurrence of symptoms in patient $2,9 \mathrm{hr}$ after being treated with praziquantel and the late and evanecent signs of pulmonary involvement (8 days after treatment with oxamniquine) observed in patient 3 (Lambertucci 1989).

It is also worth noting the consistent beneficial effect of prednisone in the cases summarized above. This is coherent with previous observations of our group (Lambertucci et al. 1989, Doenhoff et al. 1991, Lambertucci 1995).

Patient 5 had acute schistosomiasis and pyogenic liver abscesses caused by $S$. aureus. Lambertucci and colleagues have described this association in 1990 (Lambertucci et al. 1990), and recently Teixeira et al. (1996) have confirmed and extended their previous findings.

Some mechanisms have been proposed as a probable explanation for this novel and provocative association: (1) liver necrosis caused by eggs or dead worms of $S$. mansoni could be colonized by bacteria (Rocha et al. 1968), (2) there is transient impairment of the cell mediated immunity in the acute phase of schistosomiasis in animal models (Araujo et al. 1977), (3) the literature contains several reports of cases of recurrent infections caused by $S$. aureus in the presence of high IgE levels in the 
serum (Buckley et al. 1972, Lambertucci 1996), and high serum IgE levels have been reported in acute schistosomiasis.

The number of cases with the association is still rather small. More extensive use of abdominal sonography and computed tomographic scan of the abdomen, in endemic areas for schistosomiasis, will facilitate the diagnosis of liver abscess as sonography did in the case of patient 5 presented above.

\section{REFERENCES}

Amer M 1982. Cutaneous schistosomiasis. Int J Dermatol 21: 44-46.

Araujo FG, Coelho PMZ, Pereira LH, Pellegrino J 1977. Schistosoma mansoni: impairment of the cell-mediated immune response in mice. Clin Exp Immunol 28: 289-291.

Barbosa, MM, Lamounier J, Lambertucci JR 1995. Acometimento cardiopulmonar na esquistossomose. Arq bras Cardiol 65: 343-348.

Bittencourt AL, Pinho O, Lenzi HL, Costa IMC 1979. Extragenital cutaneous lesions of schistosomiasis. Am J Trop Med Hyg 28: 84-86.

Buckley RH, Wray BB, Belmaker EZ 1972. Extreme hyperimmunoglobulinemia $\mathrm{E}$ and undue susceptibility to infection. Pediatrics 49: 59-70.

Dickinson AJ, Rosenthal AR, Nicholson KG 1990. Inflammation of the retinal pigment epithelium: a unique presentation of ocular schistosomiasis. Brit $J$ Ophthalmol 74: 440-442

Doenhoff MJ, Modha J, Lambertucci JR 1988. Antischistosome chemotherapy enhanced by antibodies specific for a parasite esterase. Immunology 65: 507510.

Doenhoff MJ, Modha J, Lambertucci JR, McLaren DJ 1991. The immune dependence of chemotherapy. Parasitol Today 7: 16-18.

Gazzinelli G, Lambertucci JR, Katz N, Rocha RS, Lima MS, Colley DG 1985. Immune responses during human schistosomiasis mansoni, XI. Immunologic status of patients with acute infections and after treatment. J Immunol 135: 2121-2127.

Gelfand M 1966. Pulmonary schistosomiasis in the early "Katayama" phase of the disease. J Trop Med Hyg 69: 143-144.

Greco DB, Pedroso ERP, Lambertucci JR, Rocha MOC, Coelho PMZ, Raso P, Ferreira CS 1987. Pulmonary involvement in schistosomiasis mansoni. Mem Inst Oswaldo Cruz 82: 221-227.

Hiatt RA, Sotomayor ZR, Sanchez G, Zambrana M, Knight WB 1979. Factors in the pathogenesis of acute schistosomiasis mansoni. J Infect Dis 139: 659666.

Lambertucci JR 1989. A new approach to the treatment of acute schistosomiasis. Mem Inst Oswaldo Cruz, 84 (Suppl. I): 23-30.

Lambertucci JR 1993a. Acute schistosomiasis: clinical, diagnostic, and therapeutic features. Rev Inst Med Trop São Paulo 35: 399-404.

Lambertucci JR 1993b. Schistosoma mansoni: pathological and clinical aspects, p.195-225. In P Jordan,
G Webbe, RF Sturrock (eds). Human Schistosomiasis. Cab International, Wallingford.

Lambertucci JR 1995. Treatment of schistosomiasis: gathering stones together. Mem Inst Oswaldo Cruz 90: 161-164.

Lambertucci JR 1996. Hyperimmunoglobulinemia E, parasitic diseases and staphylococcal infection. Rev Soc Bras Med Trop 29: 407-410.

Lambertucci JR, Barata CH, Rayes AAM 1996. Unusual manifestations of acute schistosomiasis. Arq Bras Med 70: 45-49.

Lambertucci JR, Greco DB, Pedroso ERP, Rocha MOC, Salazar HM, Lima DP 1982. A double blind trial with oxamniquine in chronic schistosomiasis mansoni. Trans R Soc Trop Med Hyg 76: 751-755.

Lambertucci JR, Modha J, Curtis R, Doenhoff M 1989. The association of steroids and schistosomicides in the treatment of experimental schistosomiasis. Trans $R$ Soc Trop Med Hyg 83: 354-357.

Lambertucci JR, Pinto-Silva RA, Gerspacher-Lara R, Barata CH 1994. Acute Manson's schistosomiasis: sonographic features. Trans $R$ Soc Trop Med Hyg 88: 76-77.

Lambertucci JR, Teixeira R, Navarro MMM, Coelho PMZ, Ferreira MD 1990. Liver abscess and schistosomiasis. A new association. Rev Soc Bras Med Trop 23: 239-240.

Milligan A, Burns DA 1988. Ectopic cutaneous schistosomiasis and schistosomal ocular disease. Brit $J$ Dermatol 119: 793-798.

Neves J, Raso P, Pinto DM, Silva SP, Alvarenga RJ 1993. Ischemic colitis (necrotizing colitis, pseudomembranous colitis) in acute schistosomiasis mansoni: report of two cases. Trans $R$ Soc Trop Med Hyg 87: 449-452.

Ritchken J, Gelfand M 1954. Katayama disease, early toxaemic stage of Bilharziasis: with a report on a case showing pulmonary infiltration. Brit Med $J$ 2: 1419-1420.

Rocha H, Motta JG, Rebouças G 1968. Características da infecção por Escherichia coli em camundongos com esquistossomose mansônica. Rev Inst Med Trop São Paulo 10: 299-304.

Rocha MOC, Pedroso ERP, Greco DB, Lambertucci JR, Katz N, Rocha RL, Rocha RS, Rezende DF, Neves J 1996. Pathogenetic factors of acute schistosomiasis mansoni: correlation of worm burden, IgE, blood eosinophilia and intensity of clinical manifestations. Trop Med Intern Hlth 1: 213-220.

Taliberti BB, Ribeiro VL, Foscarini LG, Carvalho DG 1978. Apresentação clínica incomum de um caso de esquistossomose mansônica aguda. Rev Ass Med Minas Gerais 29: 23-27.

Teixeira R, Ferreira MD, Coelho PMZ, Brasileiro Filho G, Azevedo Junior GM, Lambertucci JR 1996. Pyogenic liver abscesses and acute schistosomiasis mansoni: report on 3 cases and experimental study. Trans $R$ Soc Trop Med Hyg 90: 280-283.

Zilberg B, Sanders E, Lewis B 1967. Cerebral and cardiac abnormalities in Katayama fever. South African Med J 17: 598-602. 